\title{
Editorial
}

\section{Neonatologia: ciência e arte}

\section{Neonatology: science and art}

\author{
Mário Cícero Falcão(1)
}

Considerar o recém-nascido como um paciente e tratá-lo é ato relativamente recente na prática médica. Este fato está relacionado à alta taxa de mortalidade neonatal precoce, ou seja, na primeira semana de vida, que durante muito tempo foi considerada como irreversível, pois condutas expectantes eram tomadas no sentido de se "observar" se o recém-nascido iria sobreviver.

No final do século XIX esta situação começa a ser modificada e a primeira tentativa de se reverter esta alta mortalidade resultou em uma grandiosa invenção, presente até hoje em nossas unidades neonatais - a incubadora.

Essa pequena caixa, no seu início, serviu mais para exibir pequenos prematuros do que para trata-los, porém, foi o estopim para que pudéssemos promover a homeostase térmica dos nossos recém-nascidos pré-termo, principalmente aqueles com prematuridade extrema.

Outro fato que merece destaque refere-se à criação de enfermarias específicas, destinadas às puérperas e aos recém-nascidos, reconhecendo que esse binômio requer atenção especial e portanto, não tem lugar em enfermarias comuns. Além disso, o recém-nascido, pela sua fragilidade, merece uma equipe profissional especializada para assisti-lo.

Também deve ser lembrada a introdução da nutrição parenteral, como um marco decisivo na sobrevida de recém-nascidos pré-termo e/ou doentes. Atualmente, as técnicas de nutrição parenteral, com soluções de aminoácidos e emulsões lipídicas específicas para a Neonatologia e a possibilidade de cateteres bastante sofisticados, promoveram um balanço nitrogenado positivo e um crescimento bastante semelhante ao intra-uterino. Entretanto, tal procedimento ainda não é isento de complicações, não substituindo a nutrição natural do recém-nascido, ou seja, o leite humano.

Desde os primórdios da humanidade, sabe-se que o melhor alimento para o neonato é o leite de sua própria mãe. No entanto, assistimos no século passado uma drástica queda nas taxas de aleitamento, influenciada diretamente pela sociedade. Foram criados mitos sem fundamentos científicos, onde a criança alimentada com fórmulas lácteas era mais saudável. Associou-se a isto, a necessidade da mãe exercer funções produtivas no mercado de trabalho e não dispor de tempo e nem empenho para amamentar.

Felizmente, nas últimas décadas, após inúmeras campanhas de conscientização, a mulher voltou a "gostar" de amamentar e os nossos recém-nascidos se beneficiaram com isto, pois são inquestionáveis as vantagens que o leite humano promove, salientando-se as nutricionais, imunológicas, psicossociais e no desenvolvimento neurológico.

Além do desenvolvimento e conhecimento da Nutrição, outros avanços tecnológicos e científicos contribuíram sobremaneira para a diminuição da morbimortalidade neonatal, pois,

\footnotetext{
${ }^{(1)}$ Doutor em Pediatria pela Faculdade de Medicina da Universidade de São Paulo.

Médico do Berçário Anexo à Maternidade do Hospital das Clínicas da Faculdade de Medicina da Universidade de São Paulo. Professor Colaborador da Disciplina de Pediatria Neonatal do Departamento de Pediatria da Faculdade de Medicina da Universidade de São Paulo.
}

Endereço para correspondência: R. Vieira de Moraes, 45 apto. 51. CEP 04617-010. São Paulo, S. P. e-mail: falcao@ node1.com.br 
Rev Med (São Paulo) 2003 jan.-dez.;82(1-4):i-ii.

hoje, o que nós almejamos é promover a qualidade futura da vida dos nossos recém-nascidos. $\mathrm{O}$ advento das modernas Unidades Intensivas neonatais, aliado ao aperfeiçoamento de ventiladores adequados para o período neonatal, bem como o domínio da fisiologia respiratória e de novas modalidades de suporte ventilatório, permitiu que pulmões imaturos pudessem realizar trocas gasosas satisfatórias. Ademais, a reposição do surfactante exógeno, procedimento usual hoje em dia, reverte com êxito a insuficiência respiratória da doença das membranas hialinas.

Ressalta-se também, a prevenção efetiva de infecções, através de rotinas e técnicas de anti-sepsia adequadas, principalmente nos recém-nascidos imaturos, onde o sistema imunológico é bastante ineficaz.

O aprimoramento no cuidado do recém-nascido de risco se propaga à velocidade da luz, pois técnicas que há décadas atrás sequer imaginávamos, hoje são rotinas nos mais variados Serviços. Nesse contexto inserem-se as novas técnicas de imaginologia, como a ultra-sonografia, a tomografia computadorizada e a ressonância magnética. Técnicas com diversos radioisótopos também devem ser ressaltadas, além da exsanguíneotransfusão, que reverteu o prognóstico neurológico sombrio das crianças com doença hemolítica pelo fator Rh, prevenindo de forma bastante eficaz a encefalopatia bilirrubínica.

Novos tratamentos, como a terapia com óxido nítrico inalatório, a oxigenação com membrana extracorpórea, a ventilação líquida e novas gerações de surfactantes, aliados a técnicas já consagradas como a corticoterapia ante-natal com a finalidade de amadurecer órgãos para melhorar a sobrevida e a qualidade de vida, permitindo que possamos, em futuro próximo, também lançar mão da terapia gênica.

Todos esses fatos aqui descritos, só tiveram e terão realmente o impacto esperado, porque a Obstetrícia se desenvolveu paralelamente, com a criação da Medicina Fetal, onde também o feto é encarado como paciente e novas técnicas preventivas, diagnósticas e terapêuticas já podem ser aplicadas com bastante sucesso. 